\section{Changes in dynamic lung mechanics after lung volume reduction coil treatment of severe emphysema}

\section{ABSTRACT}

We assessed the relationships between changes in lung compliance, lung volumes and dynamic hyperinflation in patients with emphysema who underwent bronchoscopic treatment with nitinol coils (coil treatment) $(n=11)$ or received usual care (UC) $(n=11)$. Compared with UC, coil treatment resulted in decreased dynamic lung compliance $\left(C_{\text {Ldyn }}\right)$ $(p=0.03)$ and increased endurance time $(p=0.010)$. The change in $C_{\text {Ldyn }}$ was associated with significant improvement in $\mathrm{FEV}_{1}$ and $F V C$, with reduction in residual volume and intrinsic positive end-expiratory pressure, and with increased inspiratory capacity at rest/ and at exercise. The increase in end-expiratory lung volume (EELV) during exercise (EELV

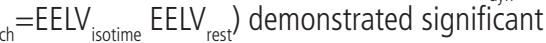
attenuation after coil treatment $(p=0.02)$.

\section{INTRODUCTION}

Lung volume reduction by coil treatment in severe emphysema aims to improve lung function, exercise capacity and quality of life. ${ }^{12}$ Memory-shaped nitinol coils are inserted into subsegmental airways, compressing local emphysematous tissue to increase elastic recoil in adjacent lung areas. Randomised controlled trials (RCT) have shown that coil treatment is superior to usual care (UC) and is associated with sustained improvements in lung function, dyspnoea and quality of life. ${ }^{3-5}$ However, the mechanism of action has not been elucidated in a dedicated study assessing the impact of coil treatment on lung mechanics. In this prospective study, we tested the hypothesis that coil treatment induces changes in lung compliance $\left(\mathrm{C}_{\mathrm{L}}\right)$ and analysed the relationships between changes in $\mathrm{C}_{\mathrm{L}}$ and in static lung volumes, dynamic hyperinflation and exercise capacity.

\section{METHODS}

Consecutive patients who participated in two successive RCTs comparing bronchoscopic bilateral treatment of emphysema with nitinol wire coils (PneumRx, California, USA) to UC were included in this prospective study. The study was approved by the institutional board of Nice University Hospital (Sud-Mediterranée V-EC-13.051); all patients gave written informed consent. Exploratory tests were conducted at baseline and at 6 months.
Pulmonary function testing was conducted with automated instrumentation (Medisoft, Belgium). Balloon mounted catheters were used to measure oesophageal, gastric pressures which allowed the measurement of lung mechanics (ie, quasi-static $\left(\mathrm{C}_{\mathrm{lst}}\right)$, dynamic lung compliance during quiet $\left(\mathrm{C}_{\text {Ldyn }}\right)$ and at rapid breathing $\left(\mathrm{C}_{\mathrm{Ldyn} \text { rap }}\right)$ ). Endurance constant-load cycle ergometry was performed to the limit of tolerance (workload at $70 \%$ of the maximal workload reached on previous test). Inspiratory capacity (IC) manoeuvres were performed every minute during ergometry. More details on methods are in the online supplementary file 1 .

\section{STATISTICAL ANALYSIS}

Normality of data distribution was assessed by the D'Agostino and Pearson omnibus normality test. Between-groups data were compared using tests for categorical or continuous variables as appropriate. Paired data were evaluated using the paired t-test or the Wilcoxon signedrank test. The relationships between variables in the coil treatment group were assessed by Pearson's or Spearman's correlation coefficient as appropriate. End-expiratory lung volume (EELV) over time was examined by repeated measures analysis of variance. A p $<0.05$ was considered statistically significant.

\section{RESULTS}

Baseline characteristics of 22 participants (coil treatment $(n=11)$ and UC $(n=11)$ ) are shown in online supplementary file 1. Compared with UC, coil treatment resulted in significant improvement in $\mathrm{FEV}_{1}(\mathrm{~L})$ median (IQR) (+0.055 $(-0.015,+0.11)$ vs $-0.030 \quad(-0.065$, $-0.030), \quad p=0.010)$ and in residual volume $(\mathrm{RV})(\mathrm{L})(1.20(-1.51,-0.21)$ vs $-0.44(-0.81,+0.39), \mathrm{p}=0.04), \mathrm{RV} /$ total lung capacity (TLC), functional residual capacity (FRC), between baseline and 6 month follow-up (table 1).

$\mathrm{C}_{\text {Ldyn }}$ significantly decreased after coil treatment compared with UC (table 1, online supplementary file 2 ). $\mathrm{C}_{\mathrm{Ldyn}}$ change $\left(\Delta \mathrm{C}_{\mathrm{Ldyn}}\right)$ in the coil treatment group correlated significantly with changes in spirometric indices $\left(\mathrm{FEV}_{1}, \mathrm{FVC}\right)$, lung volumes ( $R V$ and $\mathrm{IC}$ at rest), with $\mathrm{C}_{\mathrm{Lst}}$ and intrinsic positive end-expiratory pressure (PEEPi), and with IC and IRV at exercise (isotime) (online supplementary file 1 and supplementary file 3 ). The change (> or $\leq$ median) in FVC and RV was used to identify responders to coil treatment. Patients who increased FVC and reduced RV $(n=5)$ significantly decreased $C_{\text {Ldyn }}$ (\%change from baseline) compared with non-responders $(-23.0(-32.5,-20.0)$ vs $2.65(-13.0,+1.92), p=0.02)$. The frequency dependence of lung compliance, $C_{\text {Ldyn rap }} / \mathrm{C}_{\mathrm{Ldyn}}$, increased significantly in the coil treatment group, while no significant change was noted in the UC group (table 1).

Peak endurance time $(\Delta$ Tlim-sec $)$ significantly increased after coil treatment $(+28.50(+20.0,+38.5)$ vs +2.0 $(-15.0,+7.0), p=0.01) . \Delta$ Tlim in the coil treatment group was significantly associated with changes in $\mathrm{FEV}_{1}, \mathrm{RV}, \mathrm{RV} /$ TLC, FRC, IC-at rest, IRV-at isotime and PEEPi (online supplementary file 1). The increase in EELV during exercise (EELVdyn-ch $\left.=E E L V_{\text {isotime }}-E E L V_{\text {rest }}\right)$, a marker of dynamic hyperinflation, demonstrated significant attenuation after coil treatment $(\mathrm{p}=0.02)$ (figure 1 and online supplementary file 1).

\section{DISCUSSION}

The mechanism of action of coil treatment has not been fully understood or investigated thus far. Coils are designed to 'roll up' emphysematous lung tissue within target lobes, potentially decreasing regional volume of the hyperinflated lung. An important physiological effect of coils could be elastic lung recoil increase that could, in turn, reduce the time constant for emptying of the respiratory system and thus reduce lung hyperinflation. Our results support this hypothesis. Coil treatment improved dynamic lung mechanics as indicated by reduction in $\mathrm{C}_{\mathrm{Ldyn}}$ and reduced static lung volumes (RV, FRC and $\mathrm{RV} / \mathrm{TLC}$ ). $\mathrm{C}_{\mathrm{Ldyn}}$ reduction correlated significantly with changes in expiratory flow $\left(\mathrm{FEV}_{1}, \mathrm{FVC}\right)$ and with indices of dynamic hyperinflation (IC and IRV-at isotime).

The post-treatment reduction in RV correlated with $\Delta \mathrm{C}_{\mathrm{Ldyn}}$ and was greater than TLC reduction, thus reducing the RV/TLC ratio. We posit that expiratory muscle strength would not increase from treatment, thus RV reduction should be attributed to post-coil treatment shifts in lung compliance, resulting in decreased airway collapse and increased expiratory airflow during active expiration.

We believe this can further be explained by a larger treatment-driven improvement in dynamic versus static lung mechanics, since expiratory flow restriction is a critical determinant of $\mathrm{RV}$ in emphysematous lungs. In fact, $\Delta \mathrm{C}_{\mathrm{Ldyn}}$ in coil-treated patients was significantly correlated with changes in RV, FEV, FVC and IC at rest, whereas $\Delta \mathrm{C}_{\mathrm{Lst}}$ was not associated with any 
Table 1 Change $(\Delta)$ in lung mechanics parameters from baseline to 6 months follow-up

\begin{tabular}{|c|c|c|c|}
\hline & Coil treatment $(n=10)^{*}$ & Usual care $(n=11)$ & $\mathrm{p}$ Value \\
\hline \multicolumn{4}{|l|}{ Pulmonary function } \\
\hline$\Delta \mathrm{FEV}_{1}, \%$ pred & $+2.0(-0.5,+4.0)$ & $-1.0(-2.0,-1.0)$ & 0.01 \\
\hline$\Delta \mathrm{FVC}, \%$ pred & $+9.5(-0.20,+18.5)$ & $+5.0(-6.5,+9.3)$ & 0.31 \\
\hline$\Delta \mathrm{FEV}_{1} / \mathrm{FVC}, \%$ pred & $-1.0(-4.3,-0.25)$ & $-3.5(-4.7,-1.0)$ & 0.20 \\
\hline$\Delta \mathrm{RV}, \%$ pred & $-49.5(-62.9,-6.9)$ & $-19.0(-35.0,+17.2)$ & 0.048 \\
\hline$\triangle \mathrm{TLC}, \%$ pred & $-5.5(-15.5,-0.3)$ & $-4.0(-8.2,+0.5)$ & 0.26 \\
\hline$\triangle \mathrm{RV} / \mathrm{TLC}, \%$ pred & $-13.5(-34.5,-6.7)$ & $-3.8(-9.7,+7.6)$ & 0.043 \\
\hline$\triangle \mathrm{FRC}, \%$ pred & $-27.0(-40.5,-16.0)$ & $-6.0(-15.5,+20.2)$ & 0.03 \\
\hline \multicolumn{4}{|l|}{ Lung mechanics } \\
\hline$\Delta \mathrm{C}_{\mathrm{Lst}^{\prime}} \mathrm{L} / \mathrm{cmH}_{2} \mathrm{O}[\%]$ & $-13.1(-25.9,+4.80)$ & $+0.2(-21.1,+16.0)$ & 0.21 \\
\hline$\Delta \mathrm{C}_{\text {Ldyn' }} \mathrm{L} / \mathrm{cmH}_{2} \mathrm{O}(\%)$ & $-20.0(-24.3,-6.9)$ & $-1.3(-3.7,+1.1)$ & 0.01 \\
\hline$\Delta \mathrm{C}_{\text {Ldyn rap }} / \mathrm{C}_{\text {Ldyn }} \%$ & $+6.5(+3.7,+11.7)$ & $+1.8(-1.6,+10.4)$ & 0.043 \\
\hline$\Delta \operatorname{Res}_{\text {pulm }^{\prime}} \mathrm{cmH}_{2} \mathrm{O} / \mathrm{L} / \mathrm{s}(\%)$ & $-6.0(-11.8,-3.0)$ & $-0.9(-2.5,+8.8)$ & 0.57 \\
\hline$\triangle \mathrm{PEEPi}, \mathrm{cmH}_{2} \mathrm{O}(\%)$ & $-10.5(-17.3,-6.5)$ & $-4.8(-6.7,+13.2)$ & 0.09 \\
\hline \multicolumn{4}{|l|}{ Respiratory muscle strength } \\
\hline$\Delta$ Sniff Pes, $\mathrm{cmH}_{2} \mathrm{O}(\%)$ & $+27.8(+19.5,+43.5)$ & $-0.2(-8.0,+14.7)$ & 0.01 \\
\hline$\Delta$ Sniff Pdi, $\mathrm{cmH}_{2} \mathrm{O}(\%)$ & $+12.0(-1.4,+15.3)$ & $-1.0(-8.6,+10.4)$ & 0.052 \\
\hline
\end{tabular}

The (\%) indicates the percentage change from baseline at follow-up.

*One patient died from acute mesenteric ischaemia 1 month after coil treatment; one patient in each group has not performed test of lung mechanics at follow-up. Values represent median ( $25 \%, 75 \%$ IQR).

$p$ Value for the difference between the groups.

$\mathrm{C}_{\mathrm{Lst}}$ static lung compliance; $\mathrm{C}_{\text {Ldyn' }}$ dynamic lung compliance; $\mathrm{C}_{\text {Ldyn rap }}$ dynamic lung compliance during rapid breathing; $C_{\text {Ldyn rap }} / C_{\text {Ldyn' }}$ expresses the frequency dependence of lung compliance; FRC, functional residual capacity; Pdi, transdiaphragmatic pressure; PEEPi, intrinsic positive end-expiratory pressure; Pes, oesophageal pressure; Res $_{\text {pulm, }}$ pulmonary flow resistance; RV, residual volume; TLC, total lung capacity.

variable.

Furthermore, $\quad C_{\text {Ldynrap }} / C_{\text {Ldyn }}$ which expresses the frequency dependence of dynamic lung compliance and is considered to represent a measure of resistance to airflow in the small airways ${ }^{6}$ increased post-coil treatment; we assume that small airways were likely less prone to dynamic collapse after coil treatment. Notably, in a previous study, Kloosters et al reported decrease in volume dependent-airway resistance during dynamic conditions following coil treatment. ${ }^{7}$

In this investigation, the extent of
Tlim improvement post-coil treatment was associated with indices indicating decreased static and dynamic hyperinflation (online supplementary file 1). However, the mean Tlim increase of $29.5 \mathrm{~s}$ was rather small (ie, $60 \mathrm{~s}$ might represent a clinically significant benefit) compared
LVR-coil treatment

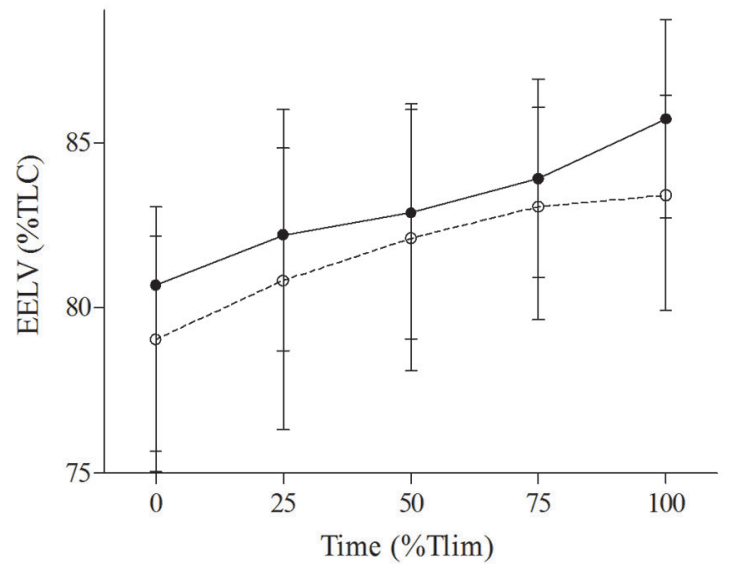

Usual Care

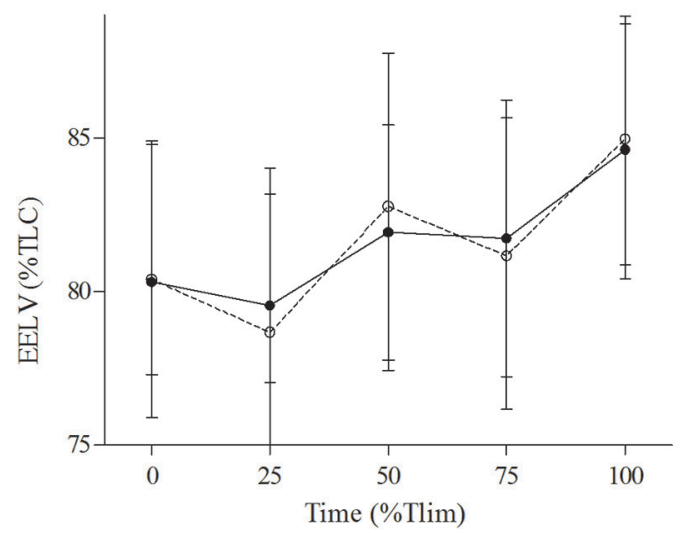

$\rightarrow$ Baseline

$-\Theta-$ Follow up

Figure 1 End-expiratory lung volume (EELV, expressed as \% of total lung capacity (TLC)) over time (expressed as \% of constant-load cycle endurance time (Tlim); 100\% Tlim is isotime) at baseline and at follow-up in coil treatment and usual care group. Data represent mean (SEM) values. 
with physiological improvements in lung function or other studies with endobronchial valve placement. ${ }^{8}$ This finding is not surprising, because exercise performance is affected by several non-respiratory organ systems (eg, musculoskeletal) and interventions to improve lung function may be of little effect on exercise capacity, where exercise tolerance is limited by leg muscle fatigue. ${ }^{910}$

Certain points should be taken into consideration when interpreting our results. Our data provide insight into the physiological changes induced by coil therapy and may provide hypothesis for future studies. The relatively small sample size may have obscured significant clinical or physiological changes between groups in some variables (ie, $\mathrm{C}_{\text {Lstat }}$ ) that a larger population might uncover and inequalities between groups (ie, age) may have influenced outcomes. In addition, technical limitations on assessment of $\mathrm{C}_{\text {Lstat }}$ (mainly assumptions of zero flow during assessment and impact of changes in operating volumes and/or intrinsic PEEP) may explain the absence of significant changes in $\mathrm{C}_{\text {Lstat }}$ in this study. The use of shutter techniques may have addressed these challenges; in fact, we used both techniques for $\mathrm{C}_{\text {Lstat }}$ assessment in a preliminary stage but due to poor patient tolerance as has been previously described, ${ }^{8} 10$ we finally used a quasi-static method.

In conclusion, our findings suggest that coil treatment reduces static lung volumes and dynamic lung hyperinflation by decreasing lung compliance and dynamic airway collapse in patients with severe emphysema.

Demosthenes Makris, ${ }^{1,2}$ Sylvie Leroy, ${ }^{2}$ Johana Pradelli, ${ }^{2}$ Jonathan Benzaquen, ${ }^{2}$ Hervé Guenard, ${ }^{3}$ Jeanne-Marie Perotin, ${ }^{4}$
Spyros Zakynthinos, ${ }^{5}$

Epaminondas Zakynthinos, ${ }^{1}$ Gaëtan Deslee, ${ }^{4}$ Charles Hugo Marquette ${ }^{2}$

${ }^{1} \mathrm{ICU}$, University Hospital Larissa, University of Thessaly, Biopolis Larissa, Greece

'Université Côte d'Azur, CHU de Nice, FHU Oncoage,

Service de Pneumologie, Nice, France

${ }^{3}$ Service d'Exploration Fonctionnelle, CHU Victor

Segalen, Bordeaux II, Bordeaux, France

${ }^{4}$ Service de Pneumologie, INSERM U903, Hôpital

Universitaire de Reims, Reims, France

${ }^{5}$ ICU, Evaggelismos University Hospital, Athens

University, Athens, Greece

Correspondence to Professor Charles

Hugo Marquette, Service de Pneumologie, Hospital

Pasteur, University Côte d'Azur, FHU OncoAge, Côte

d'Azur University, Nice 06000, France;

marquette.@@chu-nice.fr

Acknowledgements The authors wish to thank Mr Ross Robertson for his valuable assistance in editing the manuscript.

Contributors DM had full access to all of the data in the study and takes responsibility for the integrity of the data and the accuracy of the data analysis. Study concept and design: DM, SL, HG, GD and CHM. Acquisition of data: DM, SL, JP, JB and CHM. Analysis and interpretation of data: DM, SZ and EZ. Drafting of the manuscript: DM and CHM. Critical revision of the manuscript for important intellectual content: DM, SL, JB, JMP, GD and CHM. Statistical analysis: DM. Study supervision: CHM.

Funding This study was sponsored by the UNICE and the RESPIR foundations.

Competing interests None declared.

Patient consent Obtained.

Ethics approval Sud Mediterranée V - EC 13.051.

Provenance and peer review Not commissioned; externally peer reviewed.

(C) Article author(s) (or their employer(s) unless otherwise stated in the text of the article) 2018. All rights reserved. No commercial use is permitted unless otherwise expressly granted.

- Additional material is published online only. To view please visit the journal online (http://dx.doi.org/ 10.1136/thoraxjnl-2017-210118).

A Check for updates
To cite Makris D, Leroy S, Pradelli J, et al. Thorax 2018;73:584-586

Received 10 February 2017

Revised 3 July 2017

Accepted 31 July 2017

Published Online First 11 September 2017

Thorax 2018;73:584-586.

doi:10.1136/thoraxjnl-2017-210118

\section{REFERENCES}

1 Deslee G, Klooster K, Hetzel M, et al. Lung volume reduction coil treatment for patients with severe emphysema: a European multicentre trial. Thorax 2014;69:980-6

2 Shah PL, Zoumot Z, Singh S, et al. Endobronchial coils for the treatment of severe emphysema with hyperinflation (RESET): a randomised controlled trial. Lancet Respir Med 2013;1:233-40.

3 Deslée G, Mal H, Dutau H, et al. Lung volume reduction coil treatment versus standard of care in patients with severe emphysema: the REVOLENS randomized controlled trial. JAMA 2016;315:175-84.

4 Sciurba FC, Criner GJ, Strange C, et al. Effect of endobronchial coils vs usual care on exercise tolerance in patients with severe emphysema: the RENEW randomized clinical trial. JAMA 2016;315:2178-89.

5 Zoumot Z, Kemp SV, Singh S, et al. Endobronchial coils for severe emphysema are effective up to 12 months following treatment: medium term and cross-over results from a randomised controlled trial. PLOS One 2015; 10:e0122656.

6 Seaton A, Lapp NL, Morgan WK. Lung mechanics and frequency dependence of compliance in coal miners. $J$ Clin Invest 1972:51:1203-11.

7 Klooster K, Ten Hacken NH, Franz I, et al. Lung volume reduction coil treatment in chronic obstructive pulmonary disease patients with homogeneous emphysema: a prospective feasibility trial. Respiration 2014;88:116-25

8 Hopkinson NS, Toma TP, Hansell DM, et al. Effect of bronchoscopic lung volume reduction on dynamic hyperinflation and exercise in emphysema. Am J Respir Crit Care Med 2005;171:453-60

9 Saey D, Debigare R, LeBlanc P, et al. Contractile leg fatigue after cycle exercise: a factor limiting exercise in patients with chronic obstructive pulmonary disease. Am J Respir Crit Care Med 2003:168:425-30.

10 Sciurba FC, Rogers RM, Keenan RJ, et al. Improvement in pulmonary function and elastic recoil after lungreduction surgery for diffuse emphysema. $N$ Eng/ J Med 1996:334:1095-9. 